\section{RESISTENCIA DO CYSTICERCUS CELLULOSAE (GMELIN, 1790) AO CLORETO DE SÓDIO, EM PRODUTOS EMBUTIDOS ELABORADOS COM CARNES DE SUINOS INFECTADOS}

\author{
RAPHAEL VALENTINO RICCETTI \\ Professor Livre Docente \\ Faculdade de Medicina Veterinária e \\ Zootecnia da USP \\ JOSÉ CEZAR PANETTA \\ Professor Adjunto \\ Faculdade de Medicina Veterinária e \\ Zootecnia da USP
}

RICCETTI, R.V. \& PANETTA, J.C. Resistência do Cysticercus cellulosae (Gmelin, 1790) ao cloreto de sódio, em produtos embutidos elaborados com carnes de suínos infectados. Rev.Fac.Med.vet.Zootec.Univ.S. Paulo, 18(2): 153-160, 1981 .

RESUMO: Visou-se contribuir para o estudo epidemiológico e profilítico das cisticercoses animais, procurando-se verificar a resistência do Cysticercus cellulosae ao cloreto de sódio, em produto cárneo frescal elaborado segundo os padrões industriais a partir de carne suína infectada, buscando-se identificar esse produto frescal como instrumento de disseminação da teníase humana e, por conseguinte, das cisticercoses suína e humana. Pretendeuse também coligir dados que permitam formar idéia sobre as possibilidades de tratamento das carnes contaminadas pelo C. cellulosae, como também fornecer os subsídios para o aperfeicoamento e atualizacão das normas higiênico-sanitárias do Regulamento de Inspeção Industrial e Sanitária dos Produtos de Origem Animal.

UNITERMOS: Carne cisticercótica, tratamento* : Cloreto de sódio*; $^{*}$ Cisticercose*; Cysticercus cellulosae*.

\section{INTRODUÇÃO}

No presente trabalho que constitui continuação de linha de pesquisa iniciada em 1966 na Faculdade de Medicina Veterinária e Zootecnia da Universidade de São Paulo, com o objetivo de contribuir para o estudo epidemiológico e profilático das cisticercoses animais, procurou-se: 1) verificar a resistência do Cysticercus cellulosae ao cloreto de sódio, em produto cárneo frescal elaborado segundo os padrões industriais e a partir de carne suina parasitada; 2) oferecer subsídios para a devida caracterização dos produtos frescais, como instrumentos de disseminação da teníase humana e, por conseguinte, das cisticercoses suína e humana; 3) contribuir para o aperfeiçoamento e atualização das normas higiênico-sanitárias do Regulamento de Inspeção Industrial e Sanitária dos Produtos de Origem Animal; 4) coligir dados que permitam formar idéia sobre as possibilidades de tratamento das carnes contaminadas pelo $\mathrm{C}$. cellulosae.

A despeito da flutuação dos níveis de prevalência da infecção humana e suína nos diferentes paises, nenhum habitante da América Latina está livre do risco da infecção pela $\mathbf{T}$. solium ou pelo $\mathbf{C}$. cellulosae $1,3,5,13,15$.

As conclusões de SCHENONE ${ }^{13}$ parecem também posicionar definitivamente a questão sócio-econômica da cisticercose: "a cisticercose humana, que afeta o sistema nervoso central em torno de 300.000 pessoas, a ocular ao redor de 130.000 , com uma elevada taxa de-mortalidade e a cisticercose suína que produz perdas anuais da ordem de 67 milhões de dólares, constitue-se num sério problema de saúde pública na América Latina".

Tendo em conta os prejuizos econômicos advindos da condenação das carcaças contaminadas, particularmente naqueles países onde a prevalência da cisticercose suína é elevada, tem sido adotados diferentes procedimentos que visam tratamento destas carnes, de modo a possibilitar o seu aproveitamento na alimentaçăo humanal $1,5,6,8,9,10,11$

A aplicação do cloreto de sódio sob a forma de salga seca ou salmoura tem demonstrado eficiência na inativação do $C$. cellulosae $6,7,12,16$ admitindo-se que a salga seca e a salmoura concentrada $\left(25^{\circ}\right.$ Baumé) provoquem a destruição dos cistos desde que as carcaças sejam retalhadas em blocos não superiores a três quilos e que permaneçam sob a ação do cloreto de sódio por período mínimo de três semanas $2,4,7$

Merecem citação as opiniões de vários autores, a respeito da colocação do problema da cisticercose suína em termos de regulamentação e destinação das carnes contaminadas. Assim, ABDUSSALAM ${ }^{1}$, DEWHIRST ${ }^{5}$ e SHENONE13, são unânimes ao afirmarem que a legislação sobre a higiene da carne no relativo a cisticercose suína baseia-se em conceitos antiquados e em técnicas ultrapassadas. 
Os regulamentos brasileiro ${ }^{4}$, alemao ${ }^{2}$ e italiano ${ }^{7}$ admitem o uso de salmouras concentradas $\left(25^{\circ}\right.$ Baumé), para o tratamento de carnes parcialmente contaminadas pelo C. cellulosae, enquanto SCHNAAS ${ }^{14}$, enaltece a necessidade de se atualizarem os documentos sanitários, para que os mesmos possam atingir seus reais objetivos.

\section{MATERIAL E MÉTODOS}

Chegadas ao laboratório, após um transcurso de 30 minutos, as peças cárneas contaminadas eram submetidas aos cortes tradicionais de frigorífico, para a separação do tecido adiposo. Os recortes de carne foram utilizados na proporção preconizada pela formulação aprovada pelo Serviço de Inspeção Federal, ou seja: recortes de carne $75 \%$; carne de cabeça $-10 \%$ e toucinho em cubos $-15 \%$.

Nesta altura, retiravam-se das carnes, a fim de testar sua viabilidade, 20 cistos.

Posteriormente, as peças eram submetidas à moagem, em disco no. $3(9 \mathrm{~mm})$. Após a passagem pelo moinho retiravam-se novamente 20 cistos, com a intenção de se verificar qualquer interferência mecânica sobre a integridade dos mesmos. Em seguida, pesavam-se $10 \mathrm{~kg}$ da massa e adicionavam-se os ingredientes, com exceção do clore to de sódio.

Após homogeneização mecânica a massa era subdividida em 4 alíquotas de 2,5 quilos, correspondentes aos 4 tratamentos:

- no tratamento A não era adicionado cloreto de sódio (testemunho);

- no tratamento B adicionavam-se $1,25 \%$ de cloreto de sódio;

- no tratamento $\mathrm{C}$ adicionavam-se $2,5 \%$ de cloreto de sódio, quantidade empregada normalmente pelo frigorífico;

no tratamento $\mathrm{D}$ adicionavam-se $3,7 \%$ de cloreto de sódio.

Em seguida, eram os lotes dos 4 tratamentos homogeneizados separadamente, iniciando-se o embutimento, de modo que o produto era amarrado em gomos de 10 centímetros cada e deixado em temperatura ambiente (entre $15^{\circ}$ e $25^{\circ} \mathrm{C}$ ).

Posteriormente, procedia-se da seguinte forma: retirava-se um gomo $(10 \mathrm{~cm})$ do produto, incisava-se longitudinalmente e colhiam-se, casualmente, vinte cistos, com pinças tipo oftálmico, tendo-se o cuidado de recolhê-los através de suas cápsulas evitando-se qualquer lesao no escólice. Estes cistos eram colocados em placas de Petri, com o meio artificial RICCETTI ${ }^{9}, 10$ e levados à estufa a $38^{\circ} \mathrm{C}$. Posteriormente, a cada 24 horas, procedia-se a contagem dos cistos evaginados, até a obtenção de 2 resultados negativos e sucessivos.

Em outra fase procurou-se verificar, para cada tratamento, a intensidade de inativação dos cistos no tempo, seguindo-se a mesma técnica descrita na primeira fase, com a única diferença de que as leituras eram efetuadas a cada três horas.

\section{RESULTADOS}

Os resultados obtidos encontram-se condensados nas TABELAS I, II e III.

Na TABELA I, estão registrados os valores conseguidos nos testes de viabilidade do C. cellulosae, antes e após a moagem a que foram submetidos os segmentos cárneos destinados ao fabrico do produto embutido. As informações contidas nesta TABELA, demonstram a atividade das larvas de Taenia solium, encontradas nas massas musculares das carcaças parasitadas, antes e após a aplicação do agente me. cânico representado pela moagem; mostram ainda que as carcaças utilizadas apresentavam elevada percentagem de cistos viáveis $(98,75 \%)$ e que os cistos após a operação de moagem revelaram igualmente uma acentuada taxa de viabilidade $(98,25 \%)$.

Na TABELA II, incluem-se os percentuais médios de cistos viáveis resultantes da realização, em decuplicata, dos testes de evaginação dos cisticercos, aplicados a linguiça fresca de porco elaborada com carne parasitada segundo o tempo expresso em intervalos de 24 horas e o tratamento empregado.

Os dados contidos na TABELA II, demonstram que no tratamento $A$, usado como controle, a despeito do decréscimo gradual dos percentuais de viabilidade, $31,33 \%$ dos cistos examinados permaneceram viáveis a 96 horas do início do experimento. Embora não conste desta Tabela, a observação deste tratamento prosseguiu até 284 horas, quando se verificou a total inativação dos cistos examinados.

Contrariamente ao ocorrido com o tratamento $\mathrm{A}$ a inativação total dos cistos submetidos aos tratamentos $\mathrm{B}, \mathrm{C}$ e D verificou-se, respectivamente, em 72,48 e 24 horas; caracterizando ação inativante do cloreto de sódio proporcional à concentração empregada. De fato, quianto maior a quantidade de cloreto de sódio empregada, maior o percentual de cistos inativados em menor espaço de tempo.

Os elementos da TABELA II evidenciam. ainda, uma enérgica ação do clore to de sódio nas primeiras 24 horas de atuação. Mesmo na menor concentração utilizada (tratamento B), mais da metade $(57,33 \%)$ dos cistos foi inativada nesse tempo. Nos tratamentos $C$ e D, para o mesmo período as percentagens de inativação foram, respectivamente, de 77,33 e 100 .

A TABELA III agrupa os percentuais médios de cistos viáveis resultantes da realização, em decuplicata, dos testes de evaginação dos cisticercos aplicados a linguiça fresca de porco elaborada com carne parasitada, segundo o tempo de atuação, expresso em intervalos de 3 horas, e o tratamento empregado. Os valores da TABELA III permitem uma apreciação mais criteriosa da tendência temporal de inativação 
dos cistos pelo cloreto de sódio, nos diferentes tratamentos. De fato, a inativação completa dos cistos submetidos aos tratamentos B, C e D ocorreu em 45,39 e 33 horas respectivamente. Esta tendência pode ser melhor visualizada pela observação do GRÁFICO I. Este Gráfico, elaborado com base nos elementos da TABELA III, ilustra como se comportaram no tempo os percentuais de viabilidade dos cisticercos frente aos diferentes tratamentos.

Para sua construção representou-se no eixo das ordenadas, os valores percentuais médios de cistos viăveis e no das abscissas, o tempo de atuação do cloreto de sódio. Efetivamente, no tratamento $\mathrm{C}, 41,5 \%$ dos cisticercos foram inativados durante as 3 primeiras horas de contato com o cloreto de sódio, enquanto que no tratamento D. $71 \%$ destas estruturas tornaram-se inviáveis no mesmo período de tempo. Por outro lado, nota-se menor ação deste agente no tratamento $B$ e ausência de sua ação no tratamento A. Estes resultados podem ser igualmente evidenciados no GRÁFICO I.

\section{DISCUSSÃO}

A anảlise das referências bibliográficas consultadas parece suficiente para demonstrar que a legislação sobre a higiene da carne, no que concerne à cisticercose suína, baseiase em conceitos antiquados e técnicas ultrapassadas $1,5,13$, afirmação que leva à conclusão lógica de que existe carência de pesquisa no setor ${ }^{1,5}$. Efetivamente, somente será possível estabelecer normas adequadas de julgamento e destinação de carnes cisticercóticas, através de premissas técnicocientíficas em dados fiéis que possam referendar a ação dos diferentes agentes físico e químicos sobre a vitalidade do $\mathbf{C}$. cellulosae. O exame dos métodos atuais para destruir os cisticercos na carne (moagem, salga, refrigeração, congelação, defumação, ebulição) é condição básica para se aperfeiçoarem processos, os quais, confrontados com as características sócio-econômicas e ecológicas de cada região, possibilitem o controle da cisticercose e teníase humanas e a elevação da qualidade dos produtos cárneos $1,3,5,6,8,11,13,14,15$.

Revestem-se de importância os dados obtidos na TABELA I, que mostram o comportamento da vitalidade do C. cellulosae antes e após a moagem da carne em moinho equipado com disco de $9 \mathrm{~mm}$ de diâmetro, pois é conhecida a noção do efeito físico da trituração da carne sobre a integridade dos cisticercos. Poder-se-ia imaginar que a simples moagem fosse suficiente para destruir totalmente os cistos. Contudo, os resultados do controle da operação de moagem, embora não se constituindo no objetivo essencial deste trabalho, oferecem forte evidência de que este procedimento é ineficaz na inativação dos cisticercos, uma vez que de 400 cistos recolhidos após essa operação, durante as duas fases do presente estudo, $393(98,25 \%)$ revelaram-se viáveis à prova de evaginação do escólice.

Tais resultados corroboram a afirmação de JOUVÉ que assevera nåo ser a moagem um procedimento seguro pa- ra a inativação dos cisticercos, mesmo quando se utilizem discos de pequeno diâmentro. Estes conhecimentos revestem-se de elevado significado em saúde pública, particularmente no que respeita à abordagem do industrial, que poderia ser levado a concluir que a simples moagem torna inofensivo o produto elaborado com carne parasitada.

Relativamente ao efeito do cloreto de sódio, sobre a vitalidade do $\mathrm{C}$. cellulosae, os dados obtidos merecem detalhada análise, mormente quando comparados com os de outros autores e com as determinaçə̃es de alguns códigos sanitários. Assim, em trabalhos anteriores ${ }^{9,10}$, foi demonstrada a ação do cloreto de sódio usado sob a forma de salga seca, evidenciando-se que o periodo de tempo de exposição preconizado por diversos autores (SANZ EGAN̄A 12 , MANTOVANI $^{7}$, THORTON ${ }^{16}$. JOUVE ${ }^{6}$ ) e regulamentos sanitários $^{2}, 4,7$ é de amplitude exagerada, pois exigem a manutenção das carnes no agente por um espaço de tempo não inferior a três semanas, enquanto os resultados anteriores evidenciaram serem suficientes 72 horas de exposição para os cistos localizados profundamente (peças de espessura máxima de $3 \mathrm{~cm}$ ) e 24 horas para os superficiais.

Nos resultados constantes da primeira etapa deste estudo e concentrados na TABELA II nota-se a eficiente atuação do cloreto de sódio, mesmo na menor concentração utilizada (Tratamento B), pois em 72 horas houve a inativação total dos cistos examinados.

No Tratamento $\mathrm{C}$, onde se manteve a proporcionalidade de cloreto de sódio da formulação industrial đo produto, essa inativação total ocorreu em 48 horas, o que demonstra que mesmo em concentração padronizada pelo Serviço de Inspeção Federal para a elaboração de linguiça frescal de suíno, a atuação do cloreto de sódio demonstrou-se eficiente, condição esta somente admitida quando o agente era utilizado em concentrações bastante elevadas (salga seca ou salmoura a $25^{\circ} \mathrm{B}$ ).

A análise dos dados do Tratamento $\mathrm{D}$ referendam de maneira mais segura esta comprovação, pois a adição do cloreto de sódio em percentual pouco acima de $3,75 \%$ inativou totalmente os cistos em 24 horas.

Por outro lado, os resultados constantes da TABELA II são bastante significativos no que concerne à gradual atuação do cloreto de sódio sobre o $\mathbf{C}$. cellulosae. Há enérgica ação nas primeiras 24 horas, pois, no tratamento B houve inativação da ordem de $57,33 \%$, caindo esta eficiência para $28,34 \%$ nas 24 horas subsequentes. Analisando-se os Tratamentos $\mathrm{C}$ e $\mathrm{D}$ chega-se a condições ainda mais características: redução de $77,33 \%$ para 7,33\% no Tratamento $\mathrm{C}$ e de 100\% no Tratamento D.

Os resultados encontrados e comentados na primeira fase tornaram necessária a elaboração da segunda, pois o intervalo de tempo utilizado ( 24 horas) foi excessivo. Na verdade, não possuindo outros dados, a não ser os de trabalhos anteriores ${ }^{10}$, realizados com segmentos cárneos submetidos a salga seca, presumiu-se que ao se trabalhar com produtos embutidos poder-se-iam utilizar as mesmas amplitudes. Po- 
rém, esta condição não se mostrou verdadeira, pois provavelmente em virtude de no produto eleborado o cloreto de sódio distribuir-se com maior rapidez, os tempos para inativação do $\mathbf{C}$. cellulosae reduziram-se bruscamente.

No conjunto de dados oferecidos pela TABELA III pode-se observar que a atuação do cloreto de sódio coincidiu, com pequenas diferenças, com os períodos de tempo da TABELA II, flutuação que provavelmente foi ocasionada pelo grau de dessecação normal do produto, motivando pelas variaçбes da temperatura ambiental, apoiando observações de JOUVE $^{6}$ que afirma dever-se associar-se a salga à dessecação, nos países tropicais, para obter-se maior efetividade do cloreto de sódio como inativador do $\mathrm{C}$. cellulosae.

No referente ao tempo de inativação nos quatro tratamentos, objetivo da segunda fase do trabalho, verificou-se que no tratamento A (ausência de cloreto de sódio) a inativação total não foi conseguida durante o período de 48 horas, suficiente para tornar inviáveis todos os cistos em todos os outros tratamentos em que foi adicionado cloreto de sódio. As observaçð̃es prosseguiram; porém, nđ̃o constataram das TABELAS II e III apenas em razão de composição. No Tratamento $\mathrm{A}$, a inativação total somente foi alcançada após um período de 284 horas.

A análise da TABELA III apresenta outro ponto importante com relação ao Tratamento $\mathrm{A}$ : embora não fosse objeto fundamental do presente estudo, foi possivel verificar-se a ação da dessecação normal do produto sobre a viabilidade dos cisticercos. Os resultados provam que houve gradativa inativação do $\mathbf{C}$. cellulosae, em relação ao tempo, sugerindo que o agente inativador tenha sido a dessecação, pois somente após 284 horas obteve-se a inativação total.

Relativamente ao Tratamento B (TABELA III), observou-se ação inativadora crescente com o tempo do cloreto de sódio; particularmente nas primeiras três horas, pois neste periodo, foram inativados $9,5 \%$ dos cistos colhidos. A ação do cloreto de sódio continuou nas horas subsequentes, obtendo-se total inativação após 45 horas.

No Tratamento $C$, em que a concentração utilizada de cloreto de sódio correspondeu ao padrão tradicionalmente usado pela indústria, evidenciou-se enérgica atuação nas primeiras 3 horas já que de todos os cistos colhidos $41,5 \%$ mostraram-se inviáveis. A inativação total foi conseguida em 39 horas.

Os dados obtidos no Tratamento $\mathrm{D}$, em que a concentração de cloreto de sódio foi de $3,75 \%$, são bastante significativos, pois evidenciaram uma inativação de $71,0 \%$ dos cistos colhidos, num período de três horas, constatando-se inativação total em 33 horas.

A neutralização do $\mathbf{C}$. cellulosae nas três primeiras horas, nos quatro tratamentos (TABELA III), é bem evidenciada no GRÁFICO I, onde as retas correspondentes a esse período estão plenamente realçadas, percebendo-se a nítida ação inativadora do cloreto de sódio, principalmente nos Tratamentos C e D.
Os resultados registrados nas TABELAS II e III (primeira e segunda fase) devem merecer profunda análise, primeiramente no que concerne à efetiva neutralização dos $\mathrm{C}$. cellulosae, na dependência de sua concentração, e depois no que tange aos períodos de tempo preconizados pelos regulamentos sanitários, para se conseguir a inativação dos parasitas pelo agente inativador. Parece inconteste a necessidade de se reverem os critérios de rejeiça adotados pelos códigos sanitários de numerosos países, inclusive do Brasil, ao estipularem os limites de tempo que devem ser cumpridos pelas carnes cisticercóticas submetidas ao tratamento, pois os resultados do presente estudo, embora conseguidos através de um produto elaborado, são bastante discordantes daqueles documentos legais.

Assim; a maioria dos códigos estrangeiros $4,7,2$ estabelece que as carnes parasitadas pelo $C$. cellulosae devam ser submetidas à ação do cloreto de sódio, na forma de salmou. ra ou salga seca pelo período mínimo de três semanas portanto, uma concentração bem maior daquela utilizada neste trabalho. Ora, na maior concentração adotada no presente estudo $(3,75 \%)$, que se situa bem aquém da preconizada pelos códigos, a inativação total dos cisticercos foi conseguida em trinta e três horas. Note-se a discrepância de 33 horas para três semanas.

$\mathrm{O}$ regulamento sanitário brasileiro ${ }^{4}$ acompanha as exigências dos códigos estrangeiros. Em seu artigo no.176, parágrafo 2 , ítem 1 , que é extensivo às carnes suínas, determina o prazo mínimo de 21 dias em salmoura, período extremamente longo, em face dos resultados obtidos neste estudo, para a inativação do $\mathbf{C}$. cellulosae pelo clore to de sódio (33 horas).

Deve-se finalmente, analisar a posição dos embutidos frescais de carne, como a linguiça fresca de porco, na transmissão da teníase humana. Estes produtos sempre foram responsabilizados diretamente como fatores importantes na veiculação da enfermidade para o homem quando inadequa. damente elaborados, como assegura SCHNAAS ${ }^{14}$. Entretanto, os resultados presentes indicam que devam ser dispensados cuidados maiores às carnes cisticercóticas e a sua manipulação nos abatedouros, mormente no que se refere aos critérios de julgamento, destinação e tratamento pelo clore to de sódio, já que nos produtos embutidos parece ser menor a resistência do $\mathbf{C}$. cellulosae.

Estas considerações enaltecem a necessidade de pesquisas neste setor, a fim de que as autoridades possam contar com códigos sanitários apoiados em critérios científicos compativeis com as realidades sócjo-econômicas e regionais de cada país, que permitam em última análise, a vigilância eficaz das carnes rejeitadas para consumo normal e enviadas a tratamento condicional.

\section{CONCLUSÕES}


Nas condições do presente estudo e tendo em vista os resultados obtidos e comentados, parecem sustentáveis as seguintes conclusões: 10.) Existe forte evidência de que o processo de moagem da carne suína parasitada não interfere na integridade e vitalidade do C. cellulosae; 20 .) Exemplares de $\mathbf{C}$. cellulosae contidos em linguiça frescal de porco, elaborada sem a adição de cloreto de sódio, permaneceram viáveis por um período de tempo de 284 horas; 30 .) Exemplares de $\mathrm{C}$. cellulosae contidos em linguiça frescal de porco, elaborada com $1,25 \%$ de cloreto de sódio permaneceram viáveis até um periodo de tempo máximo de 45 horas; 40 .) Exemplares de $\mathbf{C}$. cellulosae contidos em linguiça frescal de porco, elaborada com a adição de $2,50 \%$ de clore to de sódio apresentaram viabilidade até um período de tempo máximo de 39 horas; 5o.) Exemplares de C. cellulosae contidos em linguiça frescal de porco elaborada com a adição de $3,75 \%$ de cloreto de sódio, foram viáveis até um período de tempo máximo de 33 horas; 6o.) A dessecação normal do produto parece interferir sobre a eficiência do cloreto de sódio, quando utilizado como agente inativador do $\mathrm{C}$. cellulosae contido em produtos embutidos de carne, havendo necessidade de estudos mais profundos que possam esclarecer esta questão; 7o.) Urge re-estudar os critérios adotados pela legislação brasileira, no que concerne às normas de julgamento e destinação das carnes cisticercóticas, bem como aos métodos permitidos para o seu aproveitamento condicional, mormente pela aplicação do cloreto de sódio; 8o.) Tendo-se em vista a eficiência do cloreto de sódio na neutralização do C. cellulosae contido em embutidos frescais de suíno, e os elevados prejuízos econômicos causados pela cisticercose suína em países economicamente carentes, parece lógica a orientação de estudos que permitam um aproveitamento adequado e seguro das carnes contaminadas.

\section{REFERENCIAS BIBLIOGRĀFICAS}

$1-$

ABDUSSALAM, M. El problema de la teniasis-cisticercosis. In: ORGANIZACIÓN PANAMERICANA DE LA SALUD. REUNIÓN INTERAMERICANA SOBRE EL CONTROL DE LA FIEBRE AFTOSA Y OTRAS ZOONOSIS, 7., Puerto España, 1974. Washington, 1975. p. 117-29. (Publicación científica, 295).

2- $\quad$ ALEMANIA. Leis, decretos, etc. Gesetz zur Anderung des Fleischbeschaugesetzes. Vom 15. Septe:nber 1969. Bonn, Bundesforschungsanstalt f.u Landwirtschaft, 1969. v.1.

3- BOLIVAR JIMÉNES, S. La cisticercosis por C. cellulosae como zoonosis. Bol.Ofic sanit.panamer., 80:403-11, 1976.

4- BRASIL. Leis, decretos, etc. Decreto no. 30.691 de 29/03/1952: aprova o novo regulamento da inspeção industrial e sanitária de produtos de origem animal. Rio de Janeiro, Ministério da Agricultura, 1953.

5- DEWHIRST, L.W. Aspectos parasitologicos y economicos de la cisticercosis en las Americas. In: ORGANIZACIÓN PANAMERICANA DE LA SALUD. REUNIÔN INTERAMERICANA SOBRE EL CONTROL DE LA FIEBRE AFTOSA Y OTRAS ZOONOSIS, 7., Puerto España, 1974. p.143-50. (Publicación científica, 295).

6- JOUVE, J.L. Modalités pratiques de l'assainissement des viandes ladres de l'espece bovine. Bull.mens.Soc.vét.prat.Fr., 60:587-602, 1976.

7- MANTOVANI, G. Inspezione degli alimenti di origini animale. Torino, Unione Tipografico-Editrice Torinese, 196I, v.1. p.990-1011

RICCETTI, R.V \& PANITTA, J.C The sodium chloride action upon the Cysticercus cellulosac (Gmelin, 1790) viability in pig meat products. Rev.Fac.Med.vet.Zootec.Univ.S. Paulo, 18(2): 153-160, 1981.

SUMMARY: This research is a contribution to the epidemiological and profilatic study of animals cysticercosis, studying the resistence of $\mathbf{C}$. cellulosae in fresh meat processed according to industrial standard and in contaminated pork meat, as a tentative of identification of this fresh meat as a disseminator of human teniasis and consequently human teniasis and cysticercosis. It was intended too, to study the possibility of treatment of contaminated pork meat with C. cellulosae as well as offer an gid to the improvement and bring up to date the hygienic sanitary standards of the Regulamentation of Sanitary and Inclustrial Inspection of Animal Origin Products.

UNITERMS : C. cell ulosae*; Cysticercosis*; Pork meat, contamination*; Sodium chloride*.
$8-$

MAZZOTTI, L.; COLORADO IRIS. R.: RAMIREZ, J.: BRISENO, C. La fritura como medio profilactico efectivo para tratar la carne cisticercosa de cerdo. Rev.Inst.Salubr.Enferm.trop., México, 21:119-24, 1961 .

9- RICCETTI, R.V. Estudo sobre a atuação do cloreto de sódio na inativação do Cysticercus cellulosae em massas musculares de suínos naturalmente infectados. Rev.Fac.Med.vet.Zootec.Univ.S. Paulo, 12:259-68, 1975.

10- RICCETTI, R.V.; PANETTA, J.C.; BARBUTO, O. 
J.M. Efeito da temperatura e do cloreto de sódio (salga seca) sobre a viabilidade do Cysticercus cellulosae em segmentos de carne suína de diferentes espessuras. Rev.Fac.Med.vet.Zootec. Univ.S. Paulo, 14:113-22, 1977.

11- ROBINSON, J.T.R. I. Observations on cysticercosis in Rhodesia. II. The survival time for Cysticercus cellulosae cysts at low temperatures. Rhod. vet.J., 7:32-5, 1976.

12- SANZ EGAÑA, C. La inspección veterinária en los mataderos, e vaquerias. Barcelona, Revista Veterinária de España, 1955. p.170-5.

13- SCHENONE, H. La cisticercosis como problema de salud humana y animal. In: ORGANIZACIÓN PANAMERICANA DE LA SALUD. REUNIÓN INTERAMERICANA SOBRE EL CON-
TROL DE LA FIEBRE AFTOSA Y OTRAS ZOONOSIS, 7., Puerto España, 1974. Washington, 1975. p.130-5. (Publicación científica, 295).

14- SCHNAAS, G. Aspectos sanitários de la cisticercosis. Gac.med.Méx., 93:1099-106, 1963.

15- SOULSBY, E.J.L. Teniasis y cisticercosis: el problema en el viejo mundo. In: ORGANIZACIÓN PANAMERICANA DE LA SALUD.

16- THORTON, H. Compêndio de inspeçâo de carnes. S.n.t., 1969. p.422-33.

Recebido para publicação em: 26-09-81 Aprovado para publicação em: 04-06-81

GRÁFICO I - Percentuais médios de cistos viáveis resultantes da realização, em decuplicata, dos testes de evaginação dos cisticercos aplicados a linguiça fresca de porco elaborada com carne parasitada segundo o tempo de atuação expresso em intervalos de 3 horas e o tratamento empregado.

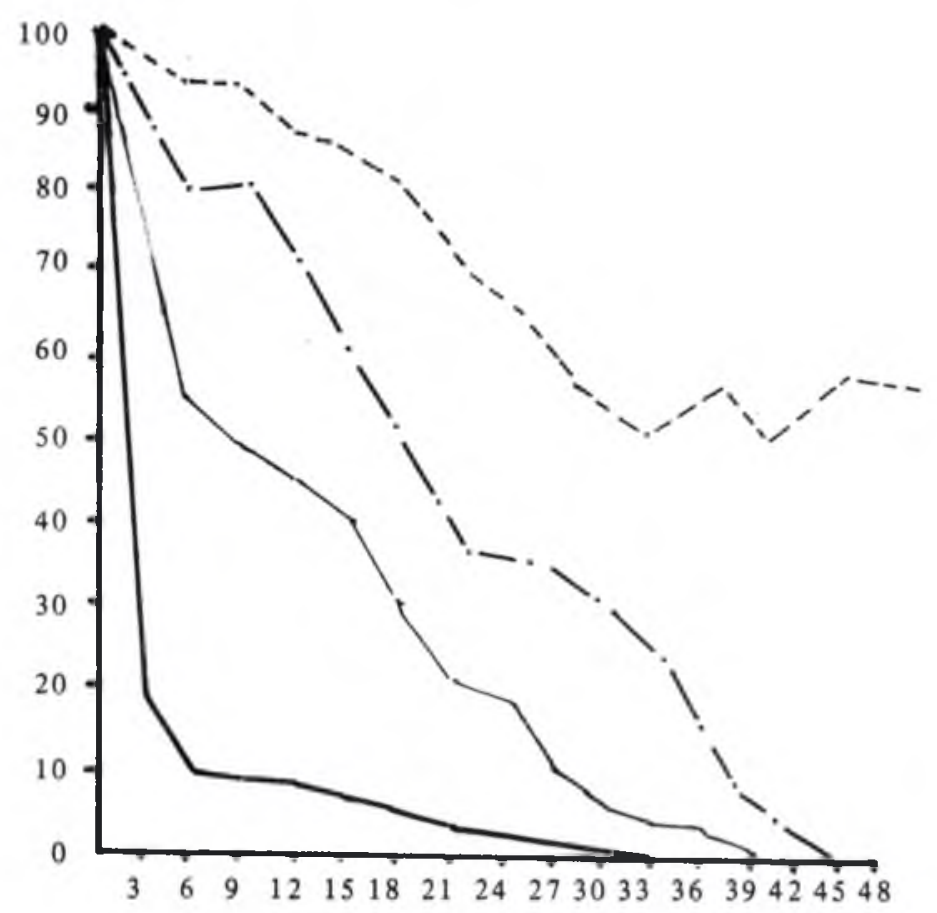


TABELA I - Resultados dos testes de viabilidade, dos Cysticercus cellulosae realizados pelo critério da evaginação, com carne parasitada de suíno, antes e depois da moagem.

\begin{tabular}{lccc}
\hline $\begin{array}{l}\text { No. de cistos } \\
\begin{array}{l}\text { Momento do } \\
\text { exame }\end{array}\end{array}$ & Examinados & Evaginados & $\%$ \\
\hline $\begin{array}{l}\text { Antes da } \\
\text { moagem }\end{array}$ & 400 & 395 & 98,75 \\
\hline $\begin{array}{l}\text { Após a } \\
\text { moagem }\end{array}$ & 400 & 393 & 98,25 \\
\hline
\end{tabular}

TABELA II - Percentuais médios de cistos viáveis resultantes da realização, em decuplicata, dos testes de evagina. ção dos cisticercos aplicados a linguiça fresca de porco elaborada com carne parasitada, segundo o tempo expresso em intervalos de 24 horas e o tratamento empregado.

\begin{tabular}{|c|c|c|c|c|}
\hline $\begin{array}{l}\text { Tratament } \\
\text { Tempo }\end{array}$ & $\mathrm{A}$ & B & $\mathrm{C}$ & D \\
\hline 0 & 93,66 & 90,33 & 84,66 & 90,00 \\
\hline 24 & 73,66 & 33,00 & 7,33 & 0 \\
\hline 48 & 55,00 & 4,66 & 0 & 0 \\
\hline 72 & 39,66 & 0 & 0 & 0 \\
\hline 96 & 31,33 & 0 & 0 & 0 \\
\hline
\end{tabular}


TABELA III - Percentuais médios de cistos viáveis resultantes da realização, em decuplicata, dos testes de evaginação dos cisticercos aplicados a linguiça fresca de porco elaborada com carne parasitada, segundo o tempo expresso em intervalos de 3 horas e o tratamento empregado.

\begin{tabular}{|c|c|c|c|c|}
\hline $\begin{array}{c}\text { Tratamento } \\
\text { Tempo }\end{array}$ & A & B & C & D \\
\hline 0 & & & & \\
3 & 97,5 & 98,5 & 97,5 & 99,0 \\
6 & 94,5 & 89,0 & 56,0 & 28,0 \\
9 & 92,0 & 83,5 & 48,0 & 13,5 \\
12 & 93,0 & 84,0 & 47,0 & 11,0 \\
15 & 89,0 & 74,0 & 43,0 & 9,5 \\
18 & 84,0 & 57,0 & 35,0 & 6,5 \\
21 & 78,5 & 50,0 & 21,0 & 4,0 \\
24 & 70,5 & 37,0 & 19,0 & 3,0 \\
27 & 62,0 & 37,0 & 16,0 & 3,5 \\
30 & 57,5 & 32,0 & 9,0 & 2,0 \\
33 & 54,5 & 21,5 & 6,5 & 0,5 \\
36 & 49,5 & 11,5 & 5,5 & 0,0 \\
39 & 46,0 & 7,5 & 5,0 & 0,0 \\
42 & 42,5 & 2,5 & 0,0 & 0,0 \\
45 & 47,5 & 1,5 & 0,0 & 0,0 \\
48 & 46,5 & 0,0 & 0,0 & 0,0 \\
& & 0,0 & 0,0 & 0,0 \\
\hline
\end{tabular}

